\title{
A relação entre teoria e prática na formação de professores de arte
}

\author{
Daniela Souza Schneider* \\ Andrea Denise Dienstmann** \\ Daniela Krummenauer ${ }^{* * *}$
}

Resumo: Neste artigo relata-se a relação entre teoria e prática desenvolvida na formação durante os cursos de graduação e pós-graduação das autoras. As autoras apresentam em comum as mesmas instituições nas quais tiveram sua formação pedagógica e profissional. O curso de graduação em Licenciatura em Ensino da Arte na Diversidade foi cursado no Centro Universitário Feevale, já o curso de pós-graduação em Metodologia do Ensino de Artes está em curso na Faculdade Internacional de Curitiba. Apresentamos uma breve explanação sobre as teorias comportamentalistas, cognitivistas e humanistas; além de um relato sobre nossa formação profissional, procurando relacioná-la às teorias de aprendizagem.

Palavras-chave: Ensino de Artes, Teorias de Aprendizagem, Formação do professor.

Abstract: In this article we report the relationship between theory and practice developed in training during the undergraduate and postgraduate of the authors. The authors have in common

* Professora substituta de Artes Visuais, do Colégio de Aplicação UFRGS em 2009 e 2010. Graduada em Ensino da Arte na Diversidade pela Universidade Feevale, RS, concluindo Especialização em Metodologia do Ensino das Artes pela Faculdade Internacional de Curitiba. E-mail: danuxass@hotmail.com

* Professora de Artes Visuais do Colégio Luterano Concórdia, São Leopoldo, RS. Graduada em Ensino da Arte na Diversidade pela Universidade Feevale, RS. E-mail: andreadienstmann@ymail.com

*** Professora de Artes Visuais do Colégio Luterano Arthur Konrath, Estância Velha, RS. Graduada em Ensino da Arte na Diversidade pela Universidade Feevale, RS. E-mail: dany.nh@ig.com.br 
the same institutions in which they had their educational and vocational training. The undergraduate program in Education of Art in Diversity was routed in the Centro Universitário Feevale, already a graduate degree in Teaching Methodology of Arts is underway at the Faculdade Internacional de Curitiba. We present a brief explanation on the behavioral theory, cognitive and humanistic; present a report on our training, trying to relate it to theories of learning.

Keywords: Teaching the Arts, Learning Theories, Teacher training.

\section{Introdução}

Este artigo aborda, a partir das teorias de aprendizagem, a relação entre teoria e prática desenvolvida em nossa formação profissional, tanto em nível de graduação como de pós-graduação.

Dentre as teorias de aprendizagem destacamos as comportamentalistas, cognitivistas e humanistas. O comportamentalismo se preocupa com os aspectos observáveis e mensuráveis do indivíduo, essas observações são aferidas através das respostas que o aprendiz dá frente a estímulos externos. Estabelece relações entre os estímulos e respostas. As primeiras abordagens comportamentalistas vieram dos teóricos Watson (1878-1958), Guthrie (1886-1959) e Thorndike (1874-1949). Mais tarde Skinner (19041990) passou a ocupar-se com o que ocorre após a resposta, isto é, com a conseqüência.

O cognitivismo se concentra na cognição do aprendiz, ou seja, se preocupa com os processos mentais como a percepção, decisões, processamento da informação e a compreensão. Uma das linhas cognitivistas é o construtivismo, dentre os principais teóricos destacamos: Piaget, Vygotsky e Ausubel. 
Já o humanismo trata o aluno enquanto pessoa, com sentimentos, pensamentos e ações. Essa filosofia tem o ensino centrado no aluno que é livre para fazer suas escolhas.

\section{O construtivismo de Vygotsky}

O teórico entende o desenvolvimento cognitivo intimamente relacionado ao contexto social, histórico e cultural onde o aprendiz está inserido.

Esse desenvolvimento mental se dá por meio de instrumentos e signos construídos socialmente nesse contexto. $\mathrm{O}$ desenvolvimento cognitivo é a conversão de relações sociais em funções mentais (MOREIRA, 1999).

Para Vygotsky, a linguagem é o principal sistema de signos que auxiliam no desenvolvimento cognitivo. Considera também que o desenvolvimento da fala é um marco importante para o desenvolvimento da linguagem.

Todo o desenvolvimento cognitivo ocorre na zona de desenvolvimento proximal que é a distância entre o nível de desenvolvimento real do indivíduo e o nível de desenvolvimento potencial. É na zona de desenvolvimento proximal (ZDP) que ocorrem as interações sociais que geram a aprendizagem. Portanto, sem a interação social, a qual ocorre na ZDP, não há desenvolvimento cognitivo.

Enfim, para Vygotsky a aprendizagem é anterior ao desenvolvimento cognitivo, o qual é impossível sem a interação social ou sem intercâmbio de significados. Na Figura 1 apresentamos um mapa conceitual ${ }^{1}$ para a teoria de Vygotsky.

1 Mapas conceituais são diagramas que expressam relações entre conceitos através de uma hierarquia na distribuição destes conceitos (MOREIRA, 2006). 


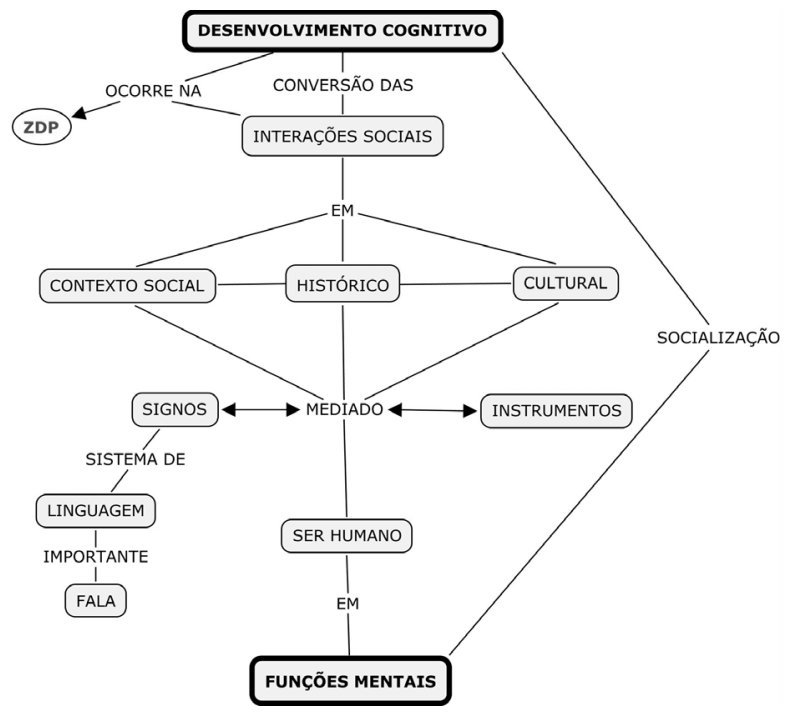

Fig. 1 - Um mapa conceitual para a teoria de aprendizagem de Vygotsky.

\section{O construtivismo de Piaget}

A teoria de Piaget é construtivista, ou seja, baseada no desenvolvimento cognitivo que se dá através da adaptação e da organização. Essa teoria está centrada na ação. Para Piaget a mente humana funciona em equilíbrio se organizando e se adaptando ao meio. Quando não há este equilíbrio por experiências que não foram assimiladas, a mente se reorganiza para chegar a um novo estado de equilíbrio, esse processo é chamado de acomodação.

Essa característica equilibradora Piaget chama de "equilibração majorante" que é imprescindível para o desenvolvimento cognitivo.

Piaget salienta a diferença qualitativa que este processo se dá na mente das pessoas de acordo com o estágio de desenvolvimento cognitivo. O professor deve respeitar o nível do desenvolvimento cognitivo em que o aprendiz se encontra, considerando as características de cada estágio. 
O período sensório-motor caracteriza-se pelo egocentrismo, o corpo é a única referência da criança, as ações não são coordenadas. O segundo período de desenvolvimento mental é o préoperatório, neste período as ações já começam a ser coordenadas e ocorre uma descentralização do sujeito. O período operatórioconcreto caracteriza-se pela descentração progressiva em relação ao egocentrismo, porém a criança ainda não trabalha com hipóteses. Já o período operatório-formal caracteriza-se principalmente pelo desenvolvimento da capacidade de raciocínio, nesta fase o sujeito trabalha com hipóteses e operações lógico-matemáticas. A Figura 2 apresenta um mapa conceitual da teoria de Piaget.

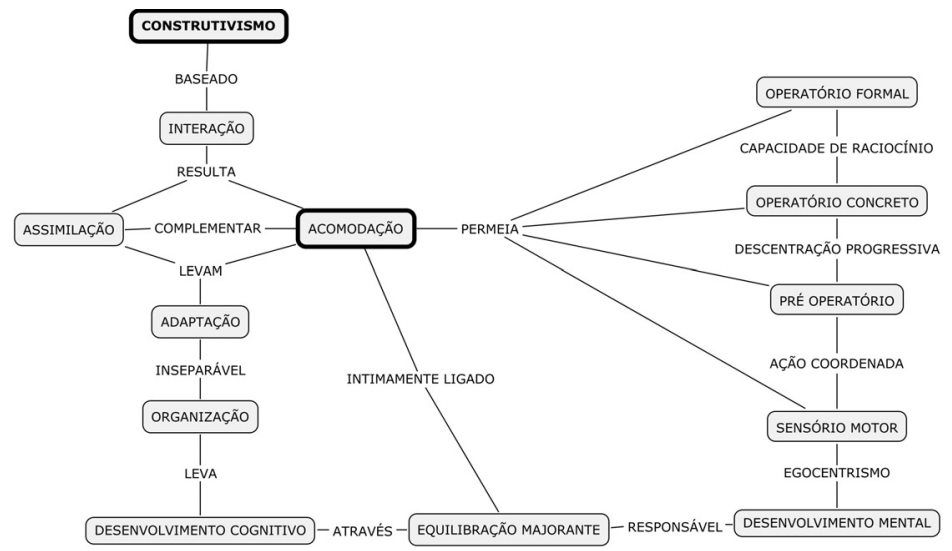

Fig. 2 - Um mapa conceitual para a teoria de aprendizagem de Piaget.

\section{A teoria da aprendizagem significativa de David Ausubel}

Para David Ausubel o fator mais importante e decisivo para a aprendizagem cognitiva é o conhecimento prévio do aprendiz. O professor deve considerar esse conhecimento e averiguá-lo já numa etapa inicial do processo de ensino. 
A aprendizagem significativa ocorrerá quando o significado do novo conhecimento vier da interação com algum conhecimento relevante preexistente na estrutura cognitiva do aprendiz. Os conceitos relevantes preexistentes na mente do aprendiz chamam-se subsunçores. O conhecimento prévio passará a ter novos significados a partir dessa interação. Se este processo ocorrer com freqüência levará à diferenciação progressiva do conceito que serviu de subsunçor (AUSUBEL, 1978 apud MOREIRA, 1999). Contudo, para tal aprendizagem ocorrer significativamente é fundamental a predisposição do aprendiz em aprender. Sobre as condições para a ocorrência da aprendizagem significativa Krummenauer salienta:

O professor deve averiguar os conhecimentos prévios dos alunos e ensinar a partir destes conhecimentos. Uma condição fundamental para a ocorrência da aprendizagem significativa é que o material utilizado esteja relacionado com a estrutura cognitiva do aluno, de maneira não-literal e não-arbitrária, desta forma o material será considerado potencialmente significativo. Independente de o material ser potencialmente significativo ou não, para ocorrer a aprendizagem significativa o aprendiz deve ter predisposição em aprender de forma significativa, para tanto o aluno não pode ter a intenção de memorizar ou decorar o material, tal postura levará à aprendizagem mecânica, isto é, sem nenhuma relação da nova informação com a estrutura cognitiva do aprendiz (KRUMMENAUER, 2009, p. 35).

O fator determinante para a aprendizagem significativa não é o modo como o aprendiz acessa o conhecimento, mas a maneira que ele se relaciona à estrutura cognitiva do aprendiz. Para ocorrer significativamente aprendizagem, a interação entre o conhecimento prévio e o novo conhecimento deve ocorrer de modo não-arbitrário e não-literal (MOREIRA, 1999).

Nesse sentido Lakomy destaca:

A aprendizagem significativa está intimamente relacionada com os pontos de ancoragem - que são formados com a incorporação, à nossa estrutura cognitiva, de conceitos, idéias ou informaçôes que são relevantes para a aquisição de novos conhecimentos, ou seja, para que possamos aprender conceitos novos. (LAKOMY, 2008, p. 63) 
Na Fig 3. apresentamos um mapa conceitual para a teoria da aprendizagem significativa de Ausubel.

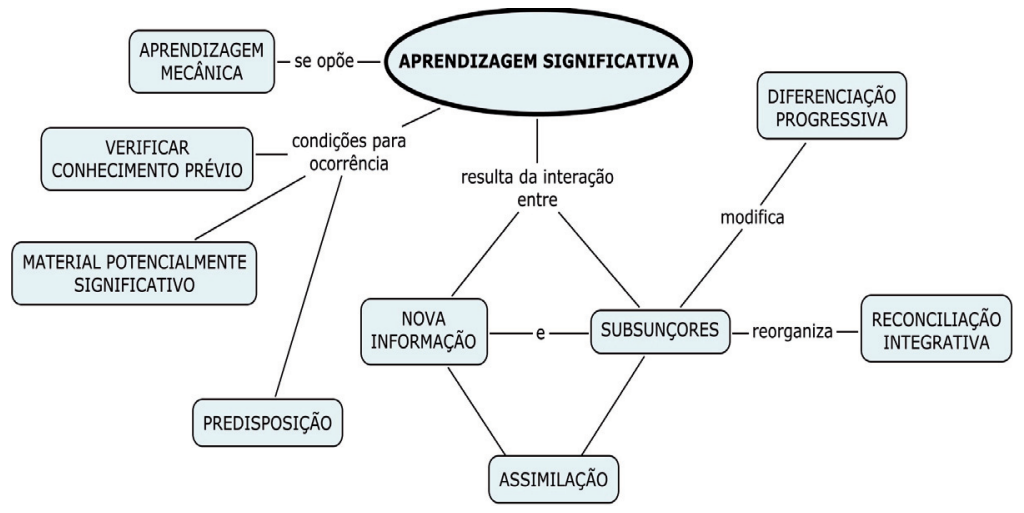

Fig. 3 - Um mapa conceitual para a teoria da aprendizagem significativa.

\section{Relação entre teoria e prática no curso de graduação}

Para podermos refletir sobre a formação continuada, precisamos antes analisar a formação inicial em nossa vida profissional. Graduadas em Ensino da Arte na Diversidade no Centro Universitário Feevale, ${ }^{2}$ realizamos um curso no qual a teoria e prática relacionam-se a cada disciplina: as aulas referentes a conteúdos educacionais, na sua maioria abrem a possibilidade dos alunos de realizarem atividades docentes e de observação em instituições de ensino formais e não-formais. As disciplinas referentes às linguagens de teatro e música, oferecem aulas práticas, nas quais o aluno, além das pesquisas de campo, experimenta atividades lúdicas e educacionais. Já as disciplinas de linguagens das artes visuais, possibilitam que os educandos explorem a percepção

2 O Centro Universitário Feevale é uma instituição de Ensino Superior da região metropolitana de Porto Alegre que oferece atualmente 42 cursos de graduação, 18 cursos de especialização, 4 de mestrado e um de doutorado. 
artística, usufruindo de atelieres estruturados com materiais e equipamentos próprios de cada linguagem.

Este contato tanto com a realidade escolar, como com espaços e estruturas ligadas à arte, certamente faz com que o ensino-aprendizagem seja mais prazeroso e dinâmico, no qual o aluno constrói seu conhecimento, idéia esta desenvolvida por Vygotsky em seus estudos. Pelas características aqui citadas percebemos uma linha pedagógica construtivista. As características construtivistas serão detalhadas nos próximos itens.

\section{Relação entre teoria e prática no curso de pós-graduação}

Fazendo-se uma reflexão e análise sobre a metodologia empregada no curso de pós-graduação da modalidade EAD do Grupo Educacional Uninter, percebemos estreita relação entre as teorias de aprendizagem e a dinâmica do curso. Embora possa parecer que a metodologia no ensino a distância possa se configurar como uma aprendizagem mecânica e comportamentalista, os recursos tecnológicos utilizados facilitam a interação entre alunoaluno e aluno-professor. Constatamos uma presença marcante das teorias construtivistas, nas quais é instigada a participação em aula, fomentada a pesquisa e o diálogo em grupo, características essas do construtivismo. Como exemplos, podemos destacar as tele-aulas, onde o ambiente permite a interação entre diferentes grupos com o professor ministrante, os chats e as tutorias via rádio, nos quais os alunos podem interagir com o professor sobre eventuais dúvidas ou dificuldades encontradas no curso.

\section{Considerações finais}

As diversas teorias de aprendizagem apresentadas aqui são fundamentais para nortear a prática educativa de todo educador. 
Nas escolas é muito comum os educadores se assumirem como construtivistas ou humanistas, porém a prática docente tem mostrado que a pedagogia das escolas tende muito mais para a aprendizagem mecânica do que para a aprendizagem significativa. As características behavioristas, apresentadas na introdução deste trabalho, parecem fazer parte do cotidiano escolar. O professor acaba exercendo muito mais um papel de instrutor do que propriamente de mediador ou educador. Talvez o pouco conhecimento de muitos educadores a respeito das teorias de aprendizagem se deva a própria falta de habilitação na área pedagógica, pois mais de um milhão de professores da educação básica não possui formação de nível superior (ROMANOWSKI, 2007).

Os cursos da modalidade educação a distância, como o curso de pós-graduação citado anteriormente, oportunizam através de ambientes virtuais de aprendizagens modernos, uma perfeita interação entre aluno e professor. Acreditamos que tanto cursos presenciais como a distância também devem ser permeados por alguma teoria de aprendizagem que possibilite ao aluno a interação e a participação e, consequentemente, contribua para uma aprendizagem significativa. No entanto, para ocorrer a aprendizagem significativa existem algumas exigências propostas por Ausubel, como por exemplo, a pré-disposição do aluno em aprender de forma significativa (MOREIRA, 1999). Outra condição para a ocorrência da aprendizagem significativa é a averiguação dos conhecimentos prévios dos aprendizes por parte do professor e um ensino coerente com essas, a partir de materiais que devem apresentar uma relação não-arbitrária e não-literal entre o conhecimento novo e o conhecimento prévio (op. cit. p. 33). 


\section{Referências}

KRUMMENAUER, Wilson Leandro. O movimento circular uniforme para alunos da EJA que trabalham no processo de produção do couro. 2009. Dissertação (Mestrado em Física) - Universidade Federal do Rio Grande do Sul, Porto Alegre, 2009.

LAKOMY, Ana Maria. Teorias cognitivas de aprendizagem. Curitiba: IBPEX, 2008.

MOREIRA, Marco Antônio. Teorias de aprendizagem. São Paulo: E.P.U., 1999.

autor, 2006.

. Mapas conceituais e diagramas V. Porto Alegre: Ed. do

ROMANOWSKI, Joana Paulin. Formação e profissionalização docente. 3 ed. Curitiba: IBPEX, 2007. 